\title{
Nas rotas da vergonha
}

\author{
Nicolas Wasser ${ }^{1}$
}

ISSN: 2358-0844

п. 12, v. 1 поv.2019-abr.2020 p. $130-142$.

RESUMO: Este texto explora diferentes rotas da vergonha e procura ilustrar como estas atuam pelo e no sexílio. A reflexão parte da posição de um sexilado europeu no Brasil, chamando atenção para a relação complexa entre afirmação e deslocamentos de uma subjetividade gay a partir de uma compreensão interseccional. Serão seguidas as rotas de sujeitos clivados por enquadramentos inconciliáveis de homossexualidade e classe, de memórias familiares alemãs da Segunda Guerra e do silêncio do colonialismo suíço para revisitar o problema das diferenças que se desdobram no complexo de raça, branquitude, língua e homossexualidade. Ao continuar na busca por uma compreensão interseccional da vergonha e dos sexílios, o texto termina com a força indestrutível de Anzaldúa, apontando para as possíveis alianças que se abrem quando afirmamos a vergonha.

PALAVRAS-CHAVE: Vergonha. Sexílio. Interseccionalidade. Afirmação de diferença. Suíça pós-colonial.

Abstract: This paper explores different routes of shame and seeks to illustrate how these act both by means of and within the sexile. The analysis is grounded on the experience of a European sexile in Brazil, focusing on the complex relationship between affirmation and movement of a gay subjectivity from an intersectional perspective. The routes of subjects split by irreconcilable framings of homosexuality and class, German WWII family memories, and the silence of Swiss colonialism are thus object of this study in order to revisit the problem of differences orchestrated by race, whiteness, language, and homosexuality. In search for an intersectional understanding of shame and sexile, the text ends with the indestructible force of Anzaldúa, indicating the possible alliances that are made available when shame is affirmed.

Keywords: Shame. Sexile. Intersectionality. Affirmation of difference. Postcolonial Switzerland.

Resumen: Este artículo examina diferentes itinerarios de la vergüenza y busca ilustrar su actuación a través del y en el sexilio. Empieza la reflexión desde la posición de un sexilado europeo en Brasil, llamando la atención para la compleja relación entre afirmación y desplazamientos de una subjetividad gay a partir de una comprensión interseccional. Y sigue las rutas de sujetos clivados por encuadres irreconciliables de homosexualidad y clase, de recuerdos familiares alemanes de la Segunda Guerra Mundial y del silencio del colonialismo suizo para volver a analizar el problema de las diferencias que se desarrollan en el complejo de raza, blanquitud, lenguaje y homosexualidad. Al seguir con la búsqueda de una comprensión interseccional de la vergüenza y del sexilio, el texto termina con la fuerza indestructible de Anzaldúa señalando las posibles alianzas que se abren cuando afirmamos la vergüenza.

Palabras clave: Vergüenza. Sexilio. Interseccionalidad. Afirmación de diferencia. Suiza postcolonial.

${ }^{1}$ Graduação em Antropologia Social e História (Universität Basel), Mestrado em Estudos Latino-Americanos (Freie Universität Berlin) e Doutorado em Sociologia (PPGSA, Instituto de Filosofia e Ciências Sociais, UFRJ). Atualmente, é pesquisador de Pós-Doutorado do Núcleo de Estudos de Gênero Pagu, da Unicamp, com financiamento da Fapesp. E-mail: nicolas.wasser@gmail.com 


\section{Introdução}

Gay. Bicha. Viado. Estas palavras-mundo não existiam na minha primeira infância. É hoje que eu escuto as suas sonoridades, as junto com ritmo e me vejo naquela criança viada que dançava Lambada - o hit mundial do final dos anos 1980 e um dos primeiros CD que tocava no recém comprado aparelho estereofônico que decorava o interior da casa geminada suíça que me contornava. Eu costumava imitar o canto desta música, com letras que nem me pareciam palavras. O que me levava era o swing da música. Mas não acessava as ideias e motivações da fala. Da mesma forma que as palavras para viado (schwuli Sau, em suíço-alemão) na época não me falavam. Na verdade, nem lembro de as ter registrado antes do Ensino Fundamental. A atração que sentia por meninos no Jardim de Infância não procurava por referenciais linguísticos. Foi mais tarde que comecei a perceber no silêncio uma resistência estranhamente profunda e vergonhosa àquilo que eu desejava.

Sexílio, na modesta literatura que o explora, recebe o sentido de diáspora. Por um lado, são focados os contextos e as experiências LGBTQI de migração (de primeira e segunda geração) de puertorriqueños e outros caribeños nos EUA, marcada por homofobia, racismo e invisibilização. Como escreve Guzmán (1997, p. 227), trata-se do "exílio daqueles que tiveram que ir embora dos seus países de origem por causa de sua orientação sexual”. Por outro lado, o sexílio também diz respeito ao deslocamento do interior para a metrópole, uma realidade já bastante comum no Brasil, e motivado pela busca LGBTQI de encontrar abrigo na cidade grande $^{2}$. Os movimentos deste texto serão um pouco diferentes, porque meu sexílio não circula pelas rotas mais traficadas. No meu caso, saem do Norte, da Europa, e pousam no Sul, no Brasil. Ao mesmo tempo, os movimentos deste sexílio cruzam tanto com deslocamentos para metrópoles quanto com a sensação de ter que ir embora do meu país - não por perseguição, mas para encontrar quadros, e talvez até linguagens além do enquadramento europeu, o qual tanto limita as possibilidades de afirmação de gays e LGBTQI.

Ao longo deste texto, serão explorados alguns dos modos pelos quais a vergonha atua no sexílio. Por meio de diferentes pesquisas e fontes, compartilho relatos subjetivos que me afetam em meu próprio sexílio, e ao mesmo tempo, transcendem e multiplicam meus afetos relativos à situação.

\footnotetext{
${ }^{2}$ Como apontou Teixeira (2015, p. 23), esse cenário teria se diversificado, pois justamente no Brasil, observava-se uma "interiorização de manifestações e sociabilidades homossexuais para além das grandes metrópoles brasileiras". No entanto, deve-se notar que, apesar desta diversificação, os centros urbanos continuam fortemente atraindo a comunidade LGBTQI, que procura mais segurança e almeja deixar para trás um contexto de vida conservador. 
Se as vergonhas de Eribon (2009) podem ajudar a mediar as clivagens na construção migratória de uma subjetividade gay, presa entre os preconceitos de classe e as discriminações sexuais (uma dupla recusa de pertencimento), estas ainda o fazem dentro de um pertencimento nacional europeu. Mas, o que acontece quando nem este está garantido? No segundo movimento, eu abordo esta questão a partir da vergonha que entra pela minha memória, uma memória até familiar, mas revisitada por olhares de sujeitos racializados. Continuando na busca por uma compreensão interseccional da vergonha e dos sexílios, eu termino, com a força indestrutível de Anzaldúa (1981, 1987), apontando para as possíveis alianças se abrindo quando afirmamos a vergonha.

2 .

Em Retour à Reims (2009), Eribon conta sua história e de sua família no interior da França a partir de suas angústias e da relação com o pai marcada tanto pela homofobia quanto pelo abismo social entre a classe operária interiorana e a sociedade parisiense. Influenciado pela proximidade a Bourdieu, Eribon explora os impasses que a incorporação de habitus provocou em sua homossexualidade. Se ele encontrou, numa paixão adolescente por um coleguinha do colégio, que era da classe média e tocava violino, uma primeira linha de fuga da opressão familiar (e que, mais tarde, ia realizar-se com a sua mudança para Paris), é na sua volta à cidade de Reims décadas mais tarde que ele se depara novamente com a melancolia ligada a um "habitus clivado".

Então vem à consciência, em tais circunstâncias, o que nós gostaríamos de acreditar estar liberado, mas nós não ignoramos que isso estrutura nossa personalidade, isto é, o malestar produzido pelo pertencer a dois mundos diferentes, um separado do outro por tanta distância que parecem irreconciliáveis, mas que coexistem em tudo o que se é3. (ERIBON, 2009, p. 14, tradução nossa)

Os dois mundos que Eribon habita são o resultado da trajetória de um menino da classe operária que resolveu virar as costas para a sua família e tornar-se intelectual em Paris. É o sentir na pele a enorme distância que separa esses dois mundos e que se revela intenso para quem entre eles transita. Mas o mal-estar não se reduz a este in-between de fronteiras de classe. Nele ecoa igualmente uma vida homossexual dentro de uma sociedade heterossexual.

3 «Affleure alors à la conscience, en de telles circonstances, ce dont on aurait aimé se croire libéré, mais dont on n'ignore pas que cela structure notre personnalité, à savoir le malaise produit par l'appartenance à deux mondes différents, séparés l'un de l'autre par tant de distance qu'ils paraissent inconciliables, mais qui coexistent néanmoins dans tout ce que l'on est $»$. 
No fundo, eu fui marcado por dois vereditos sociais: um veredito de classe e um veredito sexual. Nós nunca escapamos de tais julgamentos. E eu carrego em mim a marca dos dois. Quando eles entraram, em algum momento da minha vida, em conflito um com o outro, eu tive que me moldar jogando um contra o outro ${ }^{4}$. (ERIBON, 2009, p. 230, tradução nossa)

O sexílio, neste caso, remete a uma situação constrangedora que, buscando saídas, precisa de difamação, às vezes traição. Isso atua na língua. Torna-se a língua. Língua que nunca volta a ser a verdadeira (que desafia o verdadeiro), e por isso é condenada de ficar sob suspeito.

Eribon escreve que, quando adolescente, participava em ofender um menino da turma de tapette porque este lhes parecia afeminado. Já na época percebia que estava insultando a si mesmo e que redirecionava, imitava o uso de palavra tapette por medo da violência e vergonha que carregavam. O poder de vigilância que essa palavra (e seus parentes) desdobrava nas mentes ia voltar para o sexílio de Eribon alguns anos depois, desta vez sob o disfarce dos hábitos da língua burguesa. Os modos como os heterossexuais falavam com os homossexuais - "sem imaginar que aqueles a quem estão se dirigindo podem pertencer à espécie estigmatizada que zombam ou denigram"5 (Eribon, 2009, p. 177, tradução nossa) - tinham muito em comum com aquela agressão que irradiava da suposição dos membros da classe média de que se compartilhava as mesmas “experiências culturais e existenciais”. (Eribon, 2009, p. 177, tradução nossa)

No livro de Eribon, sobrepõem-se permanentemente dois olhares que, em seu confronto e em sua incompatibilidade, descrevem alguns dilemas do sexílio. Por um lado, a descoberta da criança viada do que ela ia se tornar ou "é" em um contexto de ódio e violência. Eis pelo poder da palavra que desdobra-se o receio: Tapette, tantouze, pédé - é o que ocasiona o estremecer que mal se faz esquecer em diante. Na narrativa autobiográfica de Eribon, fez-se necessária a aprendizagem de uma nova língua para emancipar-se, ou seja, distanciar aquelas palavras que o pai dele costumava exteriorizar quando em frente à televisão. São os mundos tecidos de um Jean Genet, as canções de Barbara, e sobretudo as áreas de cruising que iam formar a sua "escola de modos de vida e comportamento gay" (ERIBON, 2009, p. 215, tradução nossa), primeiro em Reims, e mais tarde na metrópole. Este aspecto do sexílio bem corresponde àquele deslocamento que, no seu impulso, surge pela sede por liberdade do desejo e, por vezes, pelo “objetivo simples

${ }^{4}$ «Au fond, j'étais marqué par deux verdicts sociaux: un verdict de classe et un verdict sexuel. On n'échappe jamais aux sentences ainsi rendues. Et je porte en moi la marque de l'un et de l'autre. Mais parce qu'ils entrèrent en conflit l'un avec l'autre à un moment de ma vie, je dus me façonner moi-même en jouant de l'un contre l'autre ».

5 « sans imaginer que ceux à qui ils s'adressent pourraient bien appartenir à l'espèce stigmatisée dont ils se moquent ou qu'ils dénigrent ». 
do afastar-se da família e da comunidade, para ir a um lugar onde o indivíduo não tem história”. (La Fountain-Stokes, 2004, p. 144)

Por outro lado, e esta pode ser a sensação mais angustiante diante o sexílio de Eribon, este mesmo deslocamento libertador volta a ser suspeitado. Ora porque avaliado como ato de traição da origem de classe trabalhadora e da família correspondente, ora porque deixado em silêncio - sintoma daqueles mundos da aspirada libertação de vertentes marxistas que, desde a segunda metade do século XX, tendem a tratar da (homos)sexualidade - se ainda a tratam como questão subordinada ${ }^{6}$. Em Eribon, o sexílio seria a sensação de que o passado, a origem, sempre apanha o sujeito (o retorno a Reims), mas ao mesmo tempo lhe nega o lugar, projetando o pertencimento para o outro lado, cujos parâmetros também não reconhecem a polifonia de origem e desejo. Na interpretação de Linck (2016), seria menos vergonhoso, nestes circuitos da esquerda parisiense de Eribon, ser gay do que ser da classe operária. Pois, nestes circuitos, era comum que "se é em prol do proletariado, mas naturalmente ninguém é do proletariado". (LINCK, 2016, p. 38, tradução nossa)

É contundente quando o mesmo autor lê a autobiografia de Eribon em termos de uma "politização da vergonha". Pois a narrativa sobre a experiência de afirmar a homossexualidade que coincide com a da migração para outra classe e cidade (o que eu entenderia como o sexílio de Eribon), abre um campo sensível, o do 'envergonhar-se', que não só transcende do indivíduo, mas também é capaz de transformar as relações com as outras pessoas. Com referência a Eve Kosofsky Sedgwick, Linck escreve sobre o potencial associativo do ato de encontrar a si mesmo através da vergonha dos outros:

Na vergonha que me contagia, articula-se então minha própria condição de ser possível alvo
de humilhação, e isto além de todas as diferenças que podem me separar da outra pessoa.
Na minha reação à situação do outro eu não me refiro à sua identidade, mas sinto a minha
própria vulnerabilidade e condição de ficar isolado. O que acontece nesse encontro de afetos
é o que Hubert Fichte ${ }^{7}$ chamou de 'sensibilidade'. Assumo os sentimentos do outro, os

6 Vale lembrar o impactante romance autobiográfico de Reinaldo Arenas (1993), que reflete a perseguição dos homossexuais sob o regime de Fidel Castro em Cuba, um exemplo da experiência histórica que seguia a repressão e exclusão da (homos)sexualidade do projeto revolucionário.

7 Hubert Fichte foi um poeta, antropólogo e jornalista alemão (1935-1986). Já durante a sua vida, sua vasta obra gerava inúmeras polêmicas, devido ao seu estilo não conformista e o fato de que a sua homossexualidade formava parte integral de todos os seus textos - algo muito além das convenções das décadas de 60 e 70 , seja em pesquisas antropológicas, seja na literatura alemã. De acordo com Diedrichsen (2017), Fichte usava o termo "sensibilidade" [Empfindlichkeit] para designar tanto formas de vida quanto uma postura artística (e científica) irresistente para com as realidades encontradas, na qual a homossexualidade e as relações sexuais oscilavam entre objeto e método etnográfico.

Periódicus, Salvador, n. 12, v.1, nov.2019-abr.2020 - Revista de estudos indisciplinares em gêneros e sexualidades Publicação periódica vinculada ao Núcleo de Pesquisa $\mathrm{NuCuS}$, da Universidade Federal da Bahia - UFBA ISSN: 2358-0844 - Endereço: http://www.portalseer.ufba.br/index.php/revistaperiodicus 
quais eu já conheço como meus sentimentos ruins. Somos parecidos porque podem nos destruir pela humilhação ${ }^{8}$. (LINCK, 2016, p. 46, tradução nossa)

Diante desta leitura, o sexílio de Eribon nos remete para mais do que apenas as penas do habitus clivado: projeta sentimentos e afetos que procuram laços, reconhecendo as diferenças na vulnerabilidade. Mas, a vergonha, serviria ela como linguagem que supera a clivagem, que é capaz de construir pontes?

3.

Caminante, no hay puentes, se hace puentes al andar. ${ }^{9}$

(This bridge called my back, Gloria Anzaldúa)

Minha própria biografia começa na Suíça. Aquela terrinha no coração da Europa que quer e não quer fazer parte do continente. Que - como aprendemos pela "mal-agradecida imigrante" eslovaca Irena Brežná ${ }^{10}$ - adoeceu por sua pretensão de ser uma terra escolhida, onde o mantra do sucesso material impõe, aos "outros", uma felicidade de um tanto inseguro. Não é incomum que seus vizinhos (que também me constituem) a retratem como aquilo que se aspira. Para a minha avó, alemã, os Alpes Suíços ocupavam este lugar do desejo. Lembravam-na dos passeios que fazia com o meu avô nos anos 1930, ela, jovem, no banco de trás da motocicleta. Imagino o cabelo dela ao vento. Que liberdade, que paixão era a que sentia? Naqueles anos - exatamente quando minha avó estava nos seus 20 anos - o nazismo estava tomando o poder na Alemanha. E o meu avô integrava o partido. Era por obrigação, me contavam na família quando era criança, porque senão, ele tinha que fechar a loja dele, uma pequena loja de camisas. Essa foi, para mim, a versão oficial da minha família alemã ainda quando tinha começado a cursar a Graduação. Até aparecer uma fotografia. Resgatei-a no sótão da minha avó, no meio de tralhas e caixas

\footnotetext{
8 "In der Scham, die mich ansteckt, artikuliert sich also meine eigene Beschämbarkeit, und zwar über alle Differenzen hinweg, die mich von der anderen Person trennen mögen. In meiner Reaktion auf die Lage des anderen beziehe ich mich nicht auf seine Identität, sondern erfahre meine eigene Verletzbarkeit und Isolierbarkeit. Was sich in dieser Begegnung der Affekte ereignet, nannte Hubert Fichte »Empfindlichkeit«. Ich übernehme die Gefühle des anderen, die ich als meine schlechten Gefühle bereits kenne. Wir sind uns darin ähnlich, dass man uns durch Beschämung kaputtmachen kann. (LINCK, 2016, p. 46)

${ }^{9}$ Anzaldúa refere aqui um parágrafo do poeta espanhol Antonio Machado, de 1938: "caminante, no hay camino, se hace el camino al andar".

${ }^{10}$ Irena Brežná é uma escritora suíça-eslovaca que imigrou na Suíça, em 1968, com 18 anos de idade. O seu romance parcialmente autobiográfico Die undankbare Fremde (A imigrante mal-agradecida), de 2012, ganhou o prêmio suíço de literatura e foi traduzido para diversos idiomas. 
enferrujadas. Era um retrato que mostrava os membros do partido regional (da cidade pequena deles, no Sul da Alemanha), e o meu avô estava entre eles. A fotografia era de $1931^{11}$.

As linguagens do silêncio e o disfarce da história incômoda têm sido minhas sombras íntimas desde que consigo pensar. Em um estudo intitulado Mein Opa war kein Nazi (Meu avô não era nazista), Welzer, Moller e Tschuggnall (2002) mostraram como o conhecimento da natureza criminosa-genocida do sistema nazista provoca nas gerações do pós-guerra das famílias alemãs o desejo de construir um passado em que seus próprios parentes não tivessem nada a ver com as matanças de judeus, ciganos, homossexuais, comunistas, pessoas com deficiência. Agressores tornam-se vítimas, às vezes até heróis. E por esse revezamento narrativo, o silêncio consegue encobrir não somente as mortas e perseguidas da história. Desdobra ainda uma língua que deixa a carga nos ombros de quem não era prevista, de quem manobra nas margens e para quem sobram as palavras descaradas.

May Ayim (1960-1996), poeta, educadora e ativista feminista negra alemã, chegou ao ponto quando falava sobre a inexistência de uma palavra em que ela podia caber. Filha de uma mãe alemã e de um pai ganense, cresceu em uma família adotiva, branca. Num ambiente sem referências linguísticas e subjetivas que a explicassem a sua diferença. As categorias então disponíveis - Neger (negro), Mulatte (mulata(o)), Mischling (cabrita(o), mestiça(o)) ${ }^{12}$, Besatzungskind (filha(o) da ocupação) - eram unicamente designações externas, cultivadas e atravessadas pelo vocabulário do racismo cotidiano, científico e de rescaldo ideológico-nazista. Referiam-se ou aos crimes do colonialismo/imperialismo, ou a uma nomenclatura animal ou ainda a crianças "indesejadas" que tinham surgido pela união entre homens dos Aliados (principalmente da França e dos Estados Unidos, que contavam com um número considerável de soldados negros) e mulheres alemãs brancas. May escreveu que sua adolescência era marcada pela sensação de ter que provar que um tal "mestiço" ou "negro" era um ser humano completo. (Oguntoye; Opitz; Schulz, 1986, p. 207)

Até hoje, as escritas de Ayim, e de suas coautoras negras alemãs, ainda estão longe de ser comumente lidas na zona linguística alemã. Nem na antropologia, que diz tanto querer aprender sobre si através dos olhares dos outros. Eu apenas as descobri depois do deslocamento para Berlim, onde circulavam nos debates e contextos feministas, queer e pós-coloniais, e que me

11 O regime nazista se impôs apenas em 1933, na chamada Machtergreifung (tomada do poder), que logo incluía assassinato, perseguição e deportação de qualquer oponente.

${ }^{12}$ Sigo as traduções comentadas por Kilomba (2019, p. 18). 
abriram novos mundos. Deparando-me, por Ayim, com os olhares negros dos quais fala Hooks (2019), comecei a aprender sobre o poder da perspectiva. Voltar a minha perspectiva às histórias da minha família, pelo olhar de Ayim, era retornar ao desconforto e à vergonha. O meu retorno foi, entre outros, a trechos de conversas que circulavam em reuniões familiares na minha infância. Lembro de que pediam à minha avó que contasse as histórias de uma chamada Negertrudi ${ }^{13}$, figura da vizinhança na cidade pequena dela, na época que a minha mãe e o meu tio ainda eram crianças. Sem entender do que se tratava, me provocava aquele sorriso infantil, já que me retratavam esta personagem quase como uma piada, digna de deboche. Duas décadas depois descobri que a palavra Negertrudi só podia vir dos xingamentos que uma mulher alemã no pós-guerra recebia por namorar homens negros, os soldados estacionados dos Aliados. As mesmas alianças afetivo-sexuais então vistas como inoportunas, e impregnadas na categoria Besatzungskind, estigma e sujeito tabu que Ayim ainda sentia nos anos 1970.

Misturam-se aqui as ressonâncias de duas histórias violentas do contexto alemão: a da Segunda Guerra e a do colonialismo. Como bem provoca Ayata (2016), a Alemanha ocidental pode ser vista como um "campeão mundial" no que diz respeito à recuperação do passado nazista e do Holocausto (palavras-chave aqui são a Vergangenheitsbewältigung e a Aufarbeitung), mas curiosamente não inclui uma reflexão sobre os crimes do colonialismo. Embora intelectuais e ativistas negras tenham incentivado, ao longo das últimas décadas, a discussão sobre o racismo estrutural (KILOMBA, 2019; EL-TAYEB 2011), não há reconhecimento do passado colonial na Namíbia e em outras partes do mundo em nível nacional, nem na política nem na sociedade alemã. (Ayata, 2016, p. 213) Este recalque ainda se torna mais difícil na Suíça, já que ali se argumenta que o Estado não mantinha colônias ${ }^{14}$. Segundo a teórica feminista Purtschert (2012, 2015), é esta negação que melhor define a versão suíça do póscolonialismo: um "colonialismo sem colônias" (2015) que está circulando tanto nas produções midiáticas e de propaganda quanto em contos infantis, estes projetam heróis homens brancos que salvam as africanas e africanos da barbárie e da miséria. São os mesmos contos - as fitas cassete do palhaço (Kasperli) ou de Trudi Gerster ${ }^{15}$ sobre o Negerbüebli Wumbo Wum ${ }^{16}$ - com os quais

${ }^{13}$ Em alemão, o significado, resultante composto de dois substantivos, deixa uma ambivalência na tradução para as línguas romanas. Neste caso, pode significar tanto "Gertrude preta" quanto "Gertrude do(s) preto(s)".

${ }^{14}$ Há diferentes estudos históricos que mostram grande participação de empresários suíços na economia escravocrata desde o início do colonialismo.

15 Trudi Gerster (1919-2013) foi uma atriz e famosa contadora de histórias suíça.

$16 \mathrm{O}$ conto trata de um pequeno menino negro (Wumbo Wum) que não sabe cumprir nem as tarefas mais simples, razão pela qual a sua mãe o chama de burro. Mas um dia, Wumbo Wum é atacado por um tigre e consegue matá-lo. A moral da história - já anunciado no início do conto - é que "nem todos os negros são burros", um discurso que lembra bastante os relatos de May Ayim sobre ter que provar que negros também eram humanos. Depois de críticas 
eu cresci nos anos 1980/1990. Vozes e imaginários que marcaram gerações de crianças na Suíça alemã. Apesar do vocabulário racista ter sido parcialmente retirado do mercado desde então ${ }^{17}$, é notável como a esfera pública levanta dificuldade em lidar com as críticas levantadas a este respeito desde os anos 1970. Como ainda mostra Purtschert (2012, p. 113), predomina uma postura defensiva, que oscila entre uma "preocupação paternalista ('precisamos garantir que não se exagere') e uma agressão de vitimados ('nós não somos proibidos de falar como queremos')".

Segundo Sedgwick, a vergonha ${ }^{18}$ está sempre intimamente imersa numa relação dinâmica com a identidade: pelos seus efeitos contagiosos, ela é poderosamente desconstitutiva e desafiadora aos nossos próprios conceitos do eu, e, com isso, ao nosso contexto cultural, à nossa língua (principalmente aquela usada com os "outros"), à nossa posição social no mundo, às nossas percepções (normativas) do corpo e da sexualidade, entre outros. Uma das características mais estranhas da vergonha, assim escreve Sedgwick,

\footnotetext{
é a maneira como os maus-tratos de outra pessoa, os maus-tratos por outra pessoa, o constrangimento, o estigma, a debilidade, o mau cheiro ou o comportamento estranho de outra pessoa, aparentemente não tendo nada a ver comigo, podem facilmente me inundar [...]. (2003, p. 37, tradução nossa, grifo nosso)
}

A partir desta desestabilização, a vergonha atua em dois movimentos: ela me mostra, de forma dolorosa e mais isoladora, os meus contornos individuais. Ao mesmo tempo, ela me faz perceber uma profunda relação, tanto com os outros quanto com o objeto da vergonha, da qual eu não posso fugir e que, por vezes, se apresenta de forma incontrolável.

Parece-me que muitos sexílios têm a ver com uma procura, uma tentativa em manter a vergonha à distância, em cortar suas linhas íntimas que permeiam ou, de repente, "inundam" língua, corpo, desejo. Quando penso na diferença psíquico-social daquele tipo de vergonha induzida por ofensa que me causa a palavra schwuli Sau, em suíço-alemão, em oposição a viado, em português, eu consigo apenas adivinhar o tamanho de peso que tem a língua para nos

nos anos 2000, Gerster adaptou o título do conto, trocando as palavras "pretinho burro" (vom dumme Negerli) por "africaninho" (Afrikanerli). O enredo da história, porém, continuou igual.

${ }^{17}$ Segundo Purtschert (2012, p. 101), o conto "De Schorsch Gaggo reist uf Afrika" foi retirado de circulação em 1999 e publicado, em uma versão nova, em 2000, que evita a palavra Neger.

18 Tendo relatado diferentes memórias da guerra e do colonialismo até este ponto, é importante mencionar que não é tratada aqui, em primeiro lugar, a questão da culpa. Seguindo o pensamento de Sedgwick (2003), a vergonha corresponderia a uma sensação afetiva mais confusa e anterior ao enquadramento coletivo da culpa. Ao mesmo tempo, Sedgwick enfatiza que a vergonha mexe mais imediatamente com as questões da identidade e chama para rever a culpa pelo prisma da vergonha: "as políticas da culpa serão mais bem compreendidas quando conseguirmos enxergá-las em uma relação com as dinâmicas escorregadias da vergonha”. (2003, p. 64, tradução nossa)

Periódicus, Salvador, n. 12, v.1, nov.2019-abr.2020 - Revista de estudos indisciplinares em gêneros e sexualidades Publicação periódica vinculada ao Núcleo de Pesquisa NuCuS, da Universidade Federal da Bahia - UFBA ISSN: 2358-0844 - Endereço: http://www.portalseer.ufba.br/index.php/revistaperiodicus 
situar em terrenos tão diversos como os da intimidade, do abjeto, ou da barbárie de uma “civilização". Assim, eu poderia contar meu próprio sexílio como uma história de fuga da minha própria língua e arranjo em outra. No entanto, tal narrativa não só reduziria o deslocamento à vergonha, mas também deixaria de fora a contínua relação com uma certa época, com o papel de instituições, objetos, outros afetos e, sobretudo, de outras pessoas, experiências e pensamentos envolvidos nas linguagens da vergonha.

O romance autobiográfico Wie wir begehren (Como desejamos), de Carolin Emcke ${ }^{19}$, me afeta e me faz lembrar meu Ensino Fundamental. Nele, a narradora contagia o leitor com uma vergonha em relação a um amigo no colégio, quem compartilhava com ela diferentes formas de exclusão pela turma (hipoteticamente por ser homossexual) e cuja história foi encoberta pelo silêncio. Eu tinha um amigo na minha turma - vou chamar ele aqui de Alessandro - que fora excluído de diferentes dinâmicas. Por ser adotado, por uma família de imigrantes italianos e Testemunhas de Jeová, não podia participar de aniversários de criança, nem receber presentes. Lembro que ele sempre tinha que explicar e justificar, uma criança de 7, 8 anos. Hoje, eu diria que ele era negro; na época, as categorias hegemônicas na Suíça botaram ele no papel de famílias sul-italianas, uma marca racial fora da branquitude e, ao mesmo tempo, ligada à pobreza. Anos mais tarde - e não por acaso só no momento em que eu me reconheci gay - soube a respeito dele, que havia se tornado assistente social, na área da sensibilização de HIV/Aids para homens que fazem sexo com homens. Deparei-me com a informação de que nós dois éramos as crianças viadas da turma (bem antes de saber do que se tratava).

Nesta época da escola, não era o meu suéter preferido cor-de-rosa que me tornava um estranho, mas sim a necessidade de esconder a minha parte alemã - um sotaque sutilmente diferente que perpassava a minha língua. Mesmo tendo essa experiência contínua de ter que esconder algo - o que também descreve a trajetória de tantas crianças, adolescentes e ainda adultos LGBTQI - eu não encontrava com naturalidade as tantas diferenças, das quais a minha turma era feita. De uma turma de vinte alunos, quase 3/4 eram estrangeiros ou pelo menos não $100 \%$ suíços como eu. Inunda-me a vergonha de que esse fato não era objeto da nossa consciência (além de discursos xenofóbicos). Esse "manto pesado da tolerância benevolente" (EMCKE, 2016, p. 55) cobria as histórias de tantas migrações e ainda silenciava qualquer

${ }^{19}$ Carolin Emcke é autora, jornalista e filósofa alemã. No romance Wie wir begehren, ela narra principalmente a sua juventude na Alemanha ocidental dos anos 1970 e 1980, na qual faltam termos para articular desejos, sobretudo desejos lésbicos e homossexuais. 
interesse no desejo fora da heterossexualidade. Quais teriam sido (e quais são) as possibilidades, de aliança e diferença, que continuam me ligando à história de Alessandro?

4.

A literatura minimamente crítica sobre migração e identidade trata de apontar para o pertencimento múltiplo que permeia a vida de migrantes. Em tempos nos quais ressurgem crenças em uma monotonia essencial e exclusiva da identidade (hegemônica branca), tal afirmação das identidades múltiplas é importante, apesar da sua óbvia banalidade. Mas, ao mesmo tempo, parece-me que eis aqui a diferença com o sexílio, o qual esboçamos até aqui por diferentes origens, corpos e memórias que provocam vergonha. O sexílio não se refere, primariamente, ao pertencimento múltiplo, mas exatamente ao contrário, ou seja, às múltiplas rejeições de pertencimento. Poucas pensadoras foram capazes de expressar isso - e as falsas verdades da identidade - de forma tão íntima como Anzaldúa (1981, 1987). O sexílio dela se desdobra nas terras fronteiriças (borderlands) - chicana incabível no Texas, cuja língua, cor da pele escura, performance de feminilidade e desejos lésbicos sempre significavam ou estigma ou traição à própria cultura.

Anzaldúa, em "La Prieta” (1981), tocou o campo da vergonha, por exemplo, aquela que sentia ligada ao medo de que os amigos da turma na escola pudessem ver sua mãe. Ela temia que podiam perceber que sua mãe falava alto, que comentava que ela gostava de ler livros em vez de ajudar com o trabalho doméstico, ou ainda que era aquela mãe que dava lonches para as suas crianças. (ANDALZÚA, 1981, p. 224) Diferentes indícios de que ela já era queer, a 'outra' da América branca, a tortillera, pobre, e ainda a 'prieta' indígena entre os próprios familiares mexicanos. Mas, diferente da vergonha trabalhada por Eribon, este retorno à infância em Anzaldúa não fica limitado aos impasses de uma habitus clivado. O que é cativante na obra de Anzaldúa é o seu movimento de libertação que brota do sexílio. Tanto poético quanto radical, trata-se de uma busca por uma outra língua da diferença, por uma consciência mestiza que reflete as diferentes - e muitas vezes irreconciliáveis - violações e rejeições de pertencimento.

Querendo sobrepassar o abismo e a negação, Anzaldúa oferece as próprias costas. Ela é uma construtora de pontes porque ela trabalha com a afirmação. 
(Como uma lésbica não tenho raça, meu próprio povo me rejeita; mas sou de todas as raças porque a queer em mim existe em todas as raças.) Sou sem cultura porque, como uma feminista, desafio as crenças culturais/religiosas coletivas de origem masculina dos indo-hispânicos e anglos; entretanto, tenho cultura porque estou participando da criação de uma outra cultura, uma nova história para explicar o mundo e a nossa participação nele, um novo sistema de valores com imagens e símbolos que nos conectam um/a ao/à outro/a e ao planeta" ${ }^{20}$. (ANZALDÚA, 2005, p. 707-708)

A vergonha que inunda o corpo dela não a desmotiva, mas impulsiona a disputar e autoassegurar um lugar nas diferentes culturas e línguas que lhe são (im)próprias. Toca-me no meu próprio sexílio, porque me mostra uma saída dos apertos daquela inclusão que nunca me incluiu, e também porque dissolve esta saída do caminhante individual para os braços de aliadas.

\section{Referências}

ANZALDÚA, G. La Prieta. In: MORAGA, C.; Anzaldúa, G. (org.) This bridge called my back. writings by radical women of color. Watertown: Persephone Press, 1981. p. 198-209.

ANZALDÚA, G. Borderlands/La Frontera: the new mestiza. San Francisco: Aunt Lute Books, 1987.

ANZALDÚA, G. La conciencia de la mestiza/rumo a uma nova consciência, Estudos Feministas, Florianópolis, v. 13, n. 3, p. 704-719, 2005.

ARENAS, R. Antes que anochezca. Barcelona: Tusquets, 1992.

AYATA, B. Silencing the present: Eine Postkoloniale Kritik der Aufarbeitung des NSUKomplexes. In: ZIAI, A. (org.) Postkoloniale Politikwissenschaft. Theoretische und empirische Zugänge. Bielefeld: Transcript, 2016. p. 211-234.

BREŽNÁ, I. Die undankbare Fremde. Köln: Kiepenheuer \& Witsch, 2012.

DIEDRICHSEN, D. Sexualität, Folter, Bi-Kontinentalität - Widerstand, Theorie und politische Heuristik in Hubert Fichtes Geschichte der Empfindlichkeit. Project Fichte, Lisboa, 24 out. 2017.

EL-TAYEB, F. European others. queering ethnicity in postnational Europe. Minneapolis: University of Minnesota Press, 2011.

EMCKE, C. Wie wir begehren. Frankfurt am Main: Fischer Taschenbuch, 2016.

ERIBON, D. Retour à Reims. Paris: Fayard, 2009.

GUZMÁN, M. "Pa la Escuelita con mucho cuidao y por la orillita": a journey through the contested terrains of the nation and sexual orientation. In: Negrón-Muntaner, F;

\footnotetext{
${ }^{20}$ Tradução do inglês de Ana Cecília Acioli Lima. Trecho original em Anzaldúa (1987): “As a mestiza I have no country, my homeland cast me out; yet all countries are mine because I am every women's sister or potential lover. (As a lesbian I have no race, my own people disclaim me; but I am all races because there is the queer in me in all races.) I am culturless because, as a feminist, I challenge the collective cultural/religious male-derived beliefs of Indo-Hispanics and Anglos; yet I am cultured because I am participating in the creation of another culture, a new story to explain the world and our participation in it, a new value system with new images and symbols that connect us to each other and to the planet". (ANZALDÚA, 1987, p. 103)

Periódicus, Salvador, n. 12, v.1, nov.2019-abr.2020 - Revista de estudos indisciplinares em gêneros e sexualidades Publicação periódica vinculada ao Núcleo de Pesquisa NuCuS, da Universidade Federal da Bahia - UFBA ISSN: 2358-0844 - Endereço: http://www.portalseer.ufba.br/index.php/revistaperiodicus
} 
GROSFOGUEL, R. (ed.). Puerto Rican Jam: rethinking colonialism and nationalism. Minneapolis: University of Minnesota Press, 1997. p. 209-228.

hooks, B. Olhares negros: raça e representação. São Paulo: Elefante, 2019.

KILOMBA, G. Memórias da plantação: episódios de racismo cotidiano. Rio de Janeiro: Cogobó, 2019.

LA FOUNTAIN-STOKES, L. De sexilio(s) y diáspora(s) homosexual(es) latina(s): cultura puertorriqueña y lo nuyorican "queer". Debate feminista, Cidade do México, ano 15, v. 29, p. 138-157, 2004.

LINCK, D. Die Politisierung der Scham. Didier Eribons »Rückkehr nach Reims». Merkur, [S. 1.], 1 set. 2016.

OGUNTOYE, K.; Opitz, M.; Schulz, D. (org.) Farbe bekennen. Afro-deutsche Frauen auf den Spuren ihrer Geschichte. Berlin: Orlanda Frauenverlag, 1986.

PURTSCHERT, P. »De Schorsch Gaggo reist uf Afrika«: Postkoloniale Konstellationen und diskursive Verschiebungen in Schweizer Kindergeschichten. In: PURTSCHERT, P.; Lüthi, B.; FALK, F. (org.). Postkoloniale Schweiz. Formen und Folgen eines Kolonialismus ohne Kolonien. Bielfeld: Transcript, 2012. p. 89-116.

PURTSCHERT, P.; FALK, F.; Lüthi, B. Switzerland and 'Colonialism without Colonies', Interventions, $\quad$ v. $18, \quad$ v. $2, \quad$ p. 286-302, $2015 . \quad$ DOI: http://dx.doi.org/10.1080/1369801X.2015.1042395.

SEDGWICK, E. K. Shame, theatricality, and queer performativity: Henry James's The Art of the Novel. In: SEDGWICK, E. K. Touching feeling. affect, pedagogy, performativity. London: Duke University Press, 2003. p. 35-66.

TEIXEIRA, M. A. A. "Metronormatividades" nativas: migrações homossexuais e espaços urbanos no Brasil, áskesis, São Carlos, v. 4, n. 1, p. 23-38, 2015.

WELZER, H.; MOLLER, S.; TschugGnall, K. „Opa war kein Nazi“ Nationalsozialismus und Holocaust im Familiengedächtnis. Frankfurt am Main: Fischer, 2002. 